\title{
El Motu Proprio Mitis ludex dos años después. Experiencias de su aplicación en España en materia de la investigación prejudicial o pastoral previa al proceso de nulidad matrimonial y la práctica del proceso brevior
}

Motu Proprio Mitis ludex: Two Years On. Experiences Relating to its Application in Spain in the Pre-Judicial or Pastoral Inquiry Phases, Prior to the Marriage Nullity Process, and the Briefer Process Before the Bishop in Practice

Aurora M $M^{\mathrm{a}}$ López MEDINA

Profesora Titular de Derecho Eclesiástico Universidad de Huelva. Facultad de Derecho. Huelva orcid 0000-0002-6210-9285

aurora.lopez@dthm.uhu.es

Resumen: A partir de la experiencia en la aplicación de las reformas efectuadas en el Derecho Procesal Canónico por el Motu Proprio Mitis ludex Dominus lesus, el artículo aborda los problemas que se presentan en la regulación de la investigación prejudicial o pastoral que está prevista en la Reglas Procedimentales del Motu Proprio y analiza su reflejo en la puesta en marcha del proceso brevior ante el obispo.

Palabras clave: Motu Proprio Mitis ludex Dominus lesus, Investigación prejudicial o pastoral previa, Proceso brevior.
Abstract: Drawing on experience in the application of the reformed processes relating to marriage nullity set out in the Motu Proprio Mitis ludex Dominus lesus, this article addresses the issues that arise in the regulation of the pre-judicial or pastoral inquiry phases as foreseen in procedure outlined in the Motu Proprio, and analyzes how it is reflected in the implementation of the briefer process before the bishop.

Keywords: Motu Proprio Mitis ludex Dominus lesus, Pre-Judicial or Pastoral Inquiry, Briefer Process. 


\section{Panorama de una corta experiencia}

$\mathrm{D}$ esde que el 8 de septiembre de 2015 se hizo público el contenido del Motu Proprio mediante el cual se modificaban los cánones que regulaban las causas matrimoniales en el libro V del Código de Derecho Canónico, junto al que hacía lo propio para con el Código de Cánones de las Iglesias Orientales, se ha escrito mucho sobre lo que este cambio ha significado, mejor dicho, sobre lo que ese cambio parecía que iba a significar ${ }^{1}$.

Ahora, además de los muchos artículos y libros publicados, contamos con la experiencia de su aplicación, y a la vista de ésta puede analizarse si aquello que se pretendía con la reforma se está consiguiendo y en qué modo. La experiencia ha puesto también de manifiesto algunas carencias de la propia norma. Ignoro si dos años son suficientes para valorar los resultados de la reforma operada mediante el Motu Proprio Mitis Iudex Dominus Iesus (en adelante MIDI); creo que en un sentido positivo (logros patentes), seguramente no, pero quizá dos años sea un plazo de tiempo suficiente para recordar las premoniciones que se hicieron en el momento de su promulgación y analizar cuáles no se han producido.

Las cuestiones a las que me voy a referir son dos auténticas novedades introducidas por el MIDI: la creación del nuevo procedimiento llamado brevior, regulado en los cánones 1683 a 1687, y en los arts. 14 a 20 de las Reglas de Procedimiento ${ }^{2}$ y el establecimiento de una investigación prejudicial o pastoral que se hace en los arts. 2 a 5 de estas Reglas.

Antes de continuar quiero hacer una puntualización pues, al hilo de esta reforma del proceso declarativo de nulidad matrimonial, se ha insistido mucho en una supremacía de lo pastoral sobre lo legal que recuerda a viejas pero no olvidadas enemistades entre lo pastoral y lo jurídico en la Iglesia; pues bien, no creo que se deba dar una contradicción entre lo que pertenece a uno u otro ámbito, al contrario, son dos aspectos que han de compenetrarse especialmente. No puedo dejar de recordar lo que fue una enseñanza constante del Prof. Bernárdez Cantón que hablaba siempre del Derecho como un instru-

${ }^{1}$ Queda fuera de este trabajo la aplicación del Motu Proprio Mitis et Misericors Iesus, puede verse H. Alwan, Les enjeux de l'application du Motu Proprio Mitis et misericors Iesus par les tribunaux ecclésiastiques en orient specialement au Liban, Reveu du Droit Canonique 67 (2017) 191-218.

2 El término latino utilizado es ratio procedendi. En el libro VII del CIC, en español sólo se usa la palabra reglamento al traducir del latín ordinatio. Sobre la naturaleza jurídica de esta parte de la reforma llevada a cabo por el Papa Francisco ha habido discusión desde el principio. 
mento necesario para una eficaz acción pastoral y escribía que «la norma canónica no nace al margen de las necesidades de la Iglesia, sino que sus autores, que también son pastores, la formulan de acuerdo con estas necesidades de tal manera que contiene una opción pastoral es decir la elección del medio que se considera más adecuado» ${ }^{3}$. Con este espíritu quiero acercarme al análisis de estas dos novedades introducidas por el MIDI.

Para indagar en la experiencia de la aplicación de las novedades introducidas en el proceso declarativo de nulidad matrimonial por el MIDI, cuento con unos datos que fueron presentados en las XXXVII Jornadas de la Asociación Española de Canonistas en de abril de 2017 y publicados en el volumen que recoge las actas de estas jornadas ${ }^{4}$, editado en octubre de este año. Para obtenerlos se distribuyeron unos cuestionarios entre los tribunales eclesiásticos españoles con la finalidad de recabar datos que permitieran tener idea de la repercusión que la aplicación de las normas contenidas en el Motu Proprio había tenido en nuestro país. Pues bien, la segunda de las preguntas del cuestionario se refería a los procesos más breves. Se interrogaba acerca del número de los iniciados y sobre los capítulos de nulidad invocados en estos procesos ${ }^{5}$. Prácti-

\footnotetext{
3 «Se ha pretendido también recriminar la función del Derecho Canónico so pretexto de que obstaculiza y aparta de sus fines salvíficos la acción pastoral de la Iglesia, viniéndose por este conducto a formular una pretendida incompatibilidad entre Pastoral y Derecho. Esta especie de persuasión se cae por su propio peso si pensamos que el Derecho Canónico (como el de cualquier sociedad humana) está al servicio de la propia sociedad, de la persona y de los fines específicos de una y otra. Si por Pastoral se ha de entender el arte de aplicar los medios más adecuados para la consecución de los fines de la sociedad eclesiástica, el Derecho no puede considerarse como un elemento obstaculizador de lo pastoral». A. Bernárdez Cantón, Parte General de Derecho Canónico, Centro de Estudios Ramón Areces, Madrid 1998, 37.

${ }^{4}$ R. RODRíguez CHACÓN, Resultados de la encuesta realizada por la asociación española de canonistas sobre la aplicación de MIDI en su primer año de vigencia en los tribunales eclesiásticos españoles, en L. RUANO - J. L. SÁnchez GIRÓN (eds.), Novedades de Derecho canónico y Derecho eclesiástico del Estado. A un año de la reforma del proceso matrimonial, Dykinson, Madrid 2017, 295-320. No es la primera vez que se publican datos de una encuesta realizada a los tribunales eclesiásticos españoles, conviene recordar la realizada en 1999 y que ya se cuestionaba acerca de la «relevancia de la pastoral judicial para la jerarquía diocesana», J. GALLEGO PÉREZ, Los tribunales eclesiásticos españoles, en AA. VV., Curso de Derecho matrimonial y procesal canónico para profesionales del foro. XV Simposio de Derecho matrimonial canónico, UPSA, Salamanca 2000, 431-489.

${ }^{5}$ Fueron sesenta y nueve los Vicarios judiciales a quienes se pasó el cuestionario y también se envió al Tribunal de la Rota de Madrid, y fueron cuarenta y tres las respuestas obtenidas, por consiguiente, estamos hablando de datos que corresponden a un $62,31 \%$ de los tribunales eclesiásticos españoles. Sin ser mucho, es un porcentaje que puede considerarse significativo. Pues bien, en veintiuno de ellos se han iniciado procesos breviores, y en veinte no se ha iniciado ninguno. El total de estos procesos abiertos, recuerdo que hablamos del primer año de aplicación de la nueva redacción del Código, ha sido cuarenta y nueve, de los que en el periodo treinta y cinco tuvieron sentencia, afirmativa como es consecuencia. Cuatro de ellos devinieron en proceso ordinario.
} 
camente la mitad de los tribunales que responden a la encuesta han iniciado algún proceso brevior, y por consiguiente la otra mitad no lo ha hecho. La mayor parte de los iniciados habían concluido con sentencia pro nullitate, y algunos devinieron en proceso ordinario. Esto es lo que los periodistas llamarían "situación de auténtica normalidad". Lejos quedan los augurios que prácticamente desde la tarde del 8 de septiembre de 2015 hablaban de una avalancha de nulidades ante esta "fórmula de divorcio encubierto". Algunos periódicos usaban para referirse a este nuevo proceso, la expresión "nulidad exprés", paragonándola con la del "divorcio exprés" que estuvo en boga por mor de la reforma del Código civil que permitía en España acceder al divorcio sin causa legal alguna y sin periodo de separación previo ${ }^{6}$.

¿Cuáles han sido los capítulos de nulidad invocados en estos juicios más breves? De los treinta y cinco casos que acabaron con sentencias pro nullitate, en la mayor parte de los casos, tal como señala Rodríguez Chacón, las sentencias se fundamentan en los números 2 y 3 del c. 1095. Sólo cuatro de los tribunales que han usado este procedimiento no han recurrido a este canon. Hay tres tribunales que sólo han seguidos procesos más breves por causas de simulación, en total hay ocho causas basadas en este capítulo de nulidad. Después siguen en número las causas de procesos más breves donde se invoca el dolo, y dos que se basan en error en la persona. Sólo en un caso se ha dado la nulidad por existencia de impedimento, en concreto por el contemplado en el c. 1086. Llama la atención pues, el recurso casi habitual al c. 1095.

Igual que la Asociación Española de Canonistas también su homónima italiana quiso analizar la experiencia de la aplicación del $\mathrm{MIDI}^{7}$, y gracias a la Associazione Canonistica Italiana que ha editado recientemente las actas de su

${ }^{6}$ De este modo el titular del periódico $\mathrm{ABC}$ «el arzobispo de Sevilla firma la primera sentencia de nulidad exprés» del mes de abril de 2016, contrastaba con «los obispos españoles no concederán la nulidad exprés hasta el verano» que se publicaba en el mismo periódico en noviembre de 2015. La noticia de la sentencia de Sevilla se reprodujo en todos los puntos de nuestro país. No obstante, hay que decir que meses después la prensa daría la noticia que había sido el Obispo de Bilbao quien tras un proceso que comenzó el 5 de febrero de 2016 había dado la primera nulidad exprés de España el 30 de marzo de 2016. Cuando en marzo de 2017 la prensa local recoge la noticia de la primera sentencia dada tras un proceso brevior en Málaga, ya no aparecerá la expresión «nulidad exprés».

7 También la prestigiosa Revue de Droit Canonique ha publicado en su primer número de 2017, una serie de artículos sobre el MIDI; varios de ellos se detienen en lo que ha significado su aplicación en determinados países como Suiza, Canadá, en los países africanos, la aplicación del Mitis et Misericors Iesus en el Líbano, y de un modo más concreto nos da noticias de la aplicación de procesos más breves ante el obispo en la diócesis francesa de Lille. 
XLVIII Congreso he podido conocer datos de la experiencia de la aplicación del proceso más breve no sólo en las diócesis italianas sino también en la norteamericana de Denver ${ }^{8}$ y en Alemania 9.

La aplicación del MIDI en Italia contempla una situación muy especial ante la existencia, generalizada en este país, de tribunales regionales, en los que se sustancian causas procedentes de varias diócesis. Una situación que ha condicionado la interpretación del MIDI, hasta el punto de que hubo de constituirse una Tavolo di Lavoro, una mesa de negociación, integrada por personas que interpretarían el Motu Proprio adaptándolo a la situación italiana ${ }^{10}$. Es por todo esto que la aplicación real del proceso brevior en Italia se demoró hasta el verano de 2016, momento en el cual la Conferencia Episcopal Italiana, a la vista de los resultados de las deliberaciones de los miembros de la Mesa, emitió una circular con fecha 20 de julio, aclarando que serían los obispos diocesanos respectivos y no los tribunales regionales los que se encargarían de establecer los criterios para la admisión de estos procesos y en su momento, de dar las sentencias. A partir de entonces la praxis ha sido la de admitir procesos breviores, si bien en un número bastante bajo, a fecha de septiembre de 2017 no llegaban a treinta los contabilizados ${ }^{11}$. No puede decirse que no se use este proceso, pero ciertamente hasta el momento son muy pocos los casos en los que se ha aplicado, en proporción al número de causas que se substancian en Italia ${ }^{12}$.

Por otra parte, contamos con los datos estadísticos que el Vicario judicial de Denver, EE.UU., aportó a la reunión de canonistas en Roma, en ellos fi-

${ }^{8}$ G. CAPUCCI - A. Fanella, L'attuazione del Motu Proprio Mitis Iudex Dominus Iesus nell'esperienza del tribunale metropolitano dell'arcidioceci di Denver-Colorado-USA, en AA. Vv., La riforma del processo matrimoniale ad un anno del Motu Proprio Mitis Iudex Dominus Iesus, Libreria Editrice Vaticana, Ciudad del Vaticano 2017, 173-184.

9 E. Glaubitz, L'attuazione del Motu Proprio Mitis Iudex Dominus Iesus nell'esperienza dei tribunali ecclesiastici tedeschi, en AA. Vv., La riforma del proceso matrimoniale ad un anno del Motu Proprio Mitis Iudex Dominus Iesus, Libreria Editrice Vaticana, Ciudad del Vaticano 2017, 185-193.

10 Vid. J. Llobell, Cuestiones acerca de la apelación y la cosa juzgada en el nuevo proceso de nulidad del matrimonio, Anuario de Derecho Canónico Suplemento 5 (2016) 59.

${ }^{11}$ Los datos publicados corresponden al tribunal sardo, a la diócesis de Cagliari, a la región eclesiástica de Puglia, a los tribunales regionales de Abruzo-Molisano, de Sicilia, al Vicariato de Roma, a la región eclesiástica de Piamonte y al tribunal de Calabria, AA. Vv., La riforma del processo matrimoniale ad un anno del Motu Proprio Mitis Iudex Dominus Iesus, Libreria Editrice Vaticana, Ciudad del Vaticano 2017, 195-233.

12 Quizá por esto el Santo Padre haya decidido, a modo de ejemplo, dar el mismo una sentencia mediante este proceso. La firmó el 13 de julio de 2017, aparece publicada en latín y español en P. V. PinTo, Matrimonio y Familia en el camino sinodal del Papa Francisco, Edigráficas Mariana E.U., Bogotá 2017, 89-94 y 278-283. 
guraba el número de causas que habían llegado a su tribunal en el año de aplicación de las normas del MIDI, habían sido ciento cuarenta y uno de las cuales sólo cuatro solicitaban su trámite por el proceso brevior. Hay una razón que justifica este dato: en esta diócesis se ha entendido requisito obligatorio para que se pueda seguir el trámite del proceso abreviado la realización de la investigación pre judicial-pastoral previa, en el convencimiento que ésta debe ser la única vía para determinar la evidencia de la nulidad, que requiere el Código para seguir este proceso. La práctica de esta investigación como requisito previo al proceso retrasa necesariamente el comienzo de la causa, y dado que el tiempo medio de resolver la causa en este tribunal mediante el procedimiento ordinario oscila en torno a los doce meses, quienes acuden a solicitar la nulidad no consideran el seguir el proceso brevior una mejor opción.

La experiencia en Alemania, al menos tal como la describe la juez del Tribunal Metropolitano de Colonia que intervino en la reunión de canonistas italianos, resulta muy crítica con los cambios legales propuestos en el MIDI y en relación con el proceso brevior, manifiesta que en el primer año de aplicación de la nueva normativa ningún obispo alemán ha actuado como juez en un proceso de este tipo y que ni siquiera se ha solicitado ${ }^{13}$.

Son menos los datos que se han publicado sobre la experiencia en estos años de la "investigación previa al proceso". Los que nos ofrece la encuesta realizada por la Asociación Española de Canonistas nos hablan de veintiocho tribunales que cuentan con servicio de orientación, mientras sólo doce tribunales manifiestan que carecen de éste. Entre los que afirman contar con un servicio de orientación muchos señalan que las tareas de este servicio las realizan los Centro de Orientación Familiar diocesanos, los que conocemos por las siglas COF. Estos datos contrastan con los que se obtienen en otras preguntas, y, por ejemplo, puede extrañar que dos de los tribunales que dicen no contar con servicio de orientación manifiesten que han realizado investigaciones previas. Por otra parte, al contestar al cuestionario algunos tribunales han declarado el número de consultas recibidas en los servicios de orientación o consultas, señalándolas como número de investigaciones realizadas; también ha habido casos en los que el tribunal ha respondido identificando el servicio de orientación con el establecido en virtud el art. 113 de la Instrucción Dignitas connubii, gracias al cual las personas que acuden al tribunal pidiendo infor-

13 E. GLaubitz, L'attuazione..., cit., 189. 
mación sobre la posibilidad de plantear la nulidad de su matrimonio son redirigidas a uno de los abogados inscritos en el elenco ${ }^{14}$. No está claro, para los tribunales eclesiásticos la función de los servicios de orientación en relación con los procesos de nulidad, sobre todo tras la regulación de esa fase de investigación prejudicial o pastoral en las Reglas procedimentales que acompañan al Motu Proprio.

A la vista de esto, creo que merece la pena volver sobre los temas de la investigación prejudicial o pastoral previa y de su aplicación en los procesos breviores, por resultar dos temas fundamentales dentro de la reforma y que no cuentan con una aplicación uniforme a pesar del tiempo transcurrido desde que entrara en vigor el MIDI. En primer lugar, cabe preguntarse, como se hacía en los trabajos clásicos, por el estado de la cuestión.

\section{LA INVESTIGACIÓN PREJUDICIAL O PASTORAL}

Desde un primer momento me llamó la atención esta novedad: «Se establece, en el ámbito de la pastoral matrimonial diocesana, una indagación entre los fieles separados o divorciados que dudan acerca de la validez de su matrimonio o incluso están convencidos de su nulidad. Será llevada a cabo por personas que el Ordinario del lugar considere idóneas ${ }^{15} \gg$.

Cuando tuve, en febrero de 2017, el documento elaborado en el Tribunal de la Rota Romana y que conocemos como "Subsidio Aplicativo" ${ }^{16}$, comprobé que también allí se colocaba como primer pilar de la reforma «la centralidad del obispo en el servicio a la justicia» y páginas después, al señalar «las medidas inmediatas del obispo diocesano», sitúa en primer lugar "el servicio jurídico pastoral". Más adelante este mismo documento se refiere a otro de los capisaldi de la reforma, la sinodalidad y en ese punto de puede leer: «Según la nueva ley, las conferencias episcopales organizarán un Vademécum para garantizar la organización y la uniformidad de los procedimientos, con particu-

${ }^{14}$ Esto sucede en España. En Italia la situación es diferente por mor de las Normas sobre el régimen administrativo de los tribunales eclesiásticos regionales italianos y la actividad de patrocinio desarrollada ante los mismos dictadas en 1998, publicadas con una breve reseña en Revista Española de Derecho Canónico 54 (1997) 753-771.

15 A. M. LóPEz MEDina, Actualidad del ordenamiento jurídico de la Iglesia en el año 2015, en L. RUANO - C. GuZMán (coords.), Reforma de los procesos de nulidad y otras novedades legislativas de derecho canónico y eclesiástico del Estado, Dykinson, Madrid 2017, 291.

${ }^{16}$ Uso la versión en español, Tribunal Apostólico de la Rota Romana, Subsidio Aplicativo del Motu Proprio Mitis Iudex Dominus Iesus, Ciudad del Vaticano 2016, 70 pp. 
lar atención al desarrollo de la investigación pastoral de la cual se habla más adelante». Sin embargo, no encontré desarrollo de lo previsto en relación con la investigación prejudicial.

\subsection{Su diseño}

No han faltado autores que han escrito sobre esta cuestión. Especialmente se han centrado en este tema un artículo de Enrique de León Rey, que recoge una intervención de éste en un congreso celebrado en septiembre de $2015^{17}$; otro de Arroba Conde ${ }^{18}$, también tras intervenir en unas Jornadas a raíz de la entrada en vigor del MIDI; sendos artículos de Pedro Moreno ${ }^{19} \mathrm{y}$ de Gerardo Núñez ${ }^{20}$ publicados en esta revista, otro de Francisco Regordán ${ }^{21}$, a los que hay que unir los de publicados en Italia por Constantino Fabris ${ }^{22}$ y Zanetti ${ }^{23}$, sin olvidar a otros autores que han dedicado algunas páginas a este tema en obras que han tratado de forma general temas de la reforma de las causas matrimoniales ${ }^{24}$.

Hay una serie de cuestiones que estos autores se plantean. En primer lugar, el significado canónico de esta investigación. Para encontrarlo buscan otros momentos en los que el Derecho procesal usa esta expresión, y de este modo se ha comparado con la investigación previa al juicio penal, regulada en los cc. 1717-1719 CIC $^{25}$. con las indagaciones previas a la admisión de la demanda de nulidad matrimonial que se contemplan en el art. 120 de la instruc-

17 E. DE LEÓN REY, La tramitación de los procesos de nulidad: consulta previa e inmediación, en S. SÁNChez Maldonado (ed.), IX Simposio de Derecho Matrimonial y Procesal Canónico. Granada 24 a 26 de septiembre de 2015, Arzobispado de Granada, Granada 2016, 139-150.

${ }_{18}$ M. ARroba Conde, La pastoral judicial y la preparación de la causa en el Motu Proprio Mitis Iudex Dominus Iesus, en M. E. Olmos (ed.), Procesos de nulidad matrimonial tras la reforma del Papa Francisco, Dykinson, Madrid 2016, 63-82.

19 P. A. Moreno, El servicio de indagación prejudicial, Ius Canonicum 56 (2016) 65-85.

${ }^{20}$ G. NúÑ̃Z, La fase preliminar del nuevo proceso de nulidad, Ius Canonicum 57 (2017) 9-44.

${ }^{21}$ F. J. RegORDán, La investigación preliminar en las nuevas normas procesales del Motu Proprio Mitis Iudex Dominus Iesus, Anuario de Derecho Canónico Suplemento 5 (2016) 65-85.

22 C. M. FabRIS, Indagine pregiudiziale o indagine pastorale nel Motu Proprio Mitis Iudex Dominus Iesus. Novitá normative e profili problematici, Ius Ecclesiae 28 (2016) 479-503.

23 E. ZANETTI, La consulenza previa all'introduzione di una causa, en REDAZIONE DI QUADERNI DI DIRITTO ECCLESIALE (a cura di), La riforma dei processi matrimoniali di Papa Francesco. Una guida per tutti, Ancora, Milano 2016, 9-27.

${ }^{24}$ Tal sería el caso de M. DEL POZzo, Il processo matrimoniale più breve davanti al vescovo, PUSC, Roma 2016, 151-155.

25 Vid. F. J. REgordán, La investigación..., cit., 42; G. NúÑEZ, La fase..., cit., 19. 
ción Dignitas connubii ${ }^{26}$; o con la tarea que realiza el servicio de asesoramiento con el que deben contar las curias diocesanas por mor del art. 113 de la mencionada Instrucción ${ }^{27}$. Con ello pretenden llegar a perfilar lo que estas investigaciones suponen y sobre cuál sea su finalidad. A partir de aquí los autores se preguntan acerca de quién debe encargarse de realizar esa investigación, a quiénes o a qué casos va dirigida, si debe haber una fórmula determinada de realizarlas y de cuál sea su eficacia. Sin perjuicio de las respuestas que la doctrina ha ido ofreciendo a estos interrogantes, y que pueden conocerse accediendo a los artículos citados, en mi caso intentaré recurrir a la praxis para intentar responder a las imprecisiones que se pueden apreciar tras una lectura atenta de los artículos 1 al 5 de las Reglas Procedimentales que fueron dadas por el Papa al mismo tiempo que los dos Motu Proprio ${ }^{28}$ y que como dicen en su art. 6, «no pretenden exponer minuciosamente el conjunto de todo el proceso, sino sobre todo aclarar las principales innovaciones legislativas y, donde sea necesario, integrarlas».

¿Qué papel ha tenido en la corta experiencia de aplicación del MIDI esta investigación prejudicial? Según los datos de la encuesta realizada por la Asociación Española de Canonistas, han sido ochos los tribunales que manifiestan haber recibido causas en las que se había hecho una investigación prejudicial previa. Las sumas de las investigaciones llevadas en estos ocho tribunales, según los datos de la encuesta, habían sido 69, pero sólo en seis causas se incorporaron a los autos resultados de la investigación previa. ¿Cómo podemos interpretar este dato? Se puede explicar en tanto los términos utilizados en el art. 3 de las Reglas de procedimiento dan lugar a confusión, pues de un lado se habla de "investigación" y de otro de "oficio de consulta" ${ }^{29}$. Los tribunales eclesiásticos (hay que recordar que se ha realizado la encuesta enviándola a

${ }^{26}$ G. NÚÑEZ, La fase..., cit., 16; F. J. REGORDÁN, La investigación..., cit., 42, en nota.

27 G. NúÑEZ, La fase..., cit., 18; P. A. MoRENO, El servicio..., cit., 68-69.

28 «[A]l presente documento se unen reglas de procedimiento, que he considerado necesarias para la correcta y esmerada aplicación de la ley renovada, que debe observarse diligentemente, para la tutela del bien de los fieles».

29 Dice este artículo «La misma investigación (investigatio) será confiada por el Ordinario de lugar a personas consideradas idóneas, dotadas de competencias no sólo exclusivamente jurídico-canónicas. Entre ellas están en primer lugar el párroco propio o el que ha preparado a los cónyuges para la celebración de las nupcias. Este oficio de consulta (munus hoc consulendi) puede ser confiado también a otros clérigos, consagrados o laicos aprobados por el Ordinario de lugar». En otras versiones del texto también se aprecia la diferencia entre las palabras que tienen raíz en el término «inquirir» frente a las que lo tienen en el término «consultar». De este modo encontramos en inglés inquiry vs. function of counseling o, en italiano indagine vs. compito di consulenza. 
quienes trabajan en ellos y no a las diócesis), que en su mayor parte cuentan con un servicio de asesoramiento, han entendido que las consultas que los fieles hacen en ellos, con frecuencia con la finalidad de conocer aspectos concretos de los procesos de nulidad y de saber si podrían eventualmente obtener la declaración de nulidad de su matrimonio, son investigaciones previas al proceso. Sin embargo, cuando se trata de responder sobre el número de casos en los que en estas investigaciones se han recopilado datos para presentar en la causa, la encuesta habla que esto sólo ha sucedido en seis ocasiones. Cabe pensar que se refieran a casos, pocos, en los que no sólo se ha tratado de consulta, sino que se ha seguido una fase de investigación acerca de la posible duda sobre la validez del matrimonio. Aunque también se ha dado un tipo de respuesta diferente, pues de entre los doce tribunales que declaran no contar con un servicio de orientación, dos de ellos manifiestan que han seguido causas en las que se había realizado una investigación previa. En estos casos el tribunal parece distinguir la consulta de las indagaciones prejudiciales y no relacionan los servicios de información general del tribunal con la investigación pastoral que puede llevar a entablar un proceso de nulidad.

\subsection{Quiénes la realizan}

Otro dato de la experiencia que nos puede ilustrar acerca de cómo se ha entendido la investigación prejudicial es analizar quiénes la están realizando. En los tribunales españoles, como se ha dejado apuntado, prevalece la idea de que se trata de una tarea que desarrollan las oficinas de asesoramiento incardinadas en los tribunales, que se constituyeron tras la Dignitas connubii. Es cierto que estas oficinas nunca han sido diseñadas de una manera uniforme. Tampoco se ha hecho una interpretación o mejor, una adaptación del c. $1490^{30}$. No se hizo a pesar de que los arts. 112 y 113 de la Dignitas connubii mencionaban este canon, distinguiendo entre abogados del elenco y abogados estables, como tampoco se ha hecho en el MIDI, a pesar de tratarse de un canon que se refie-

${ }^{30}$ Desde la doctrina se ha interpretado restrictivamente el alcance de esta prescripción. Refiriéndose a los abogados o patronos estables, se ha escrito: «Dicho oficio, en efecto, aunque abundantemente utilizado en algunos países, es completamente extraño a otras culturas jurídicas (p. ej., la italiana). Por otra parte, la constitución de este oficio se había hecho necesaria por los extravíos que había provocado la ausencia de una clase forense privada en algunos países (me refiero al Este europeo durante el periodo de dominación comunista)». Cfr. C. Gullo, Comentario al can. 1490, en Comentario Exegético al Código de Derecho Canónico, Eunsa, Pamplona 1997, vol. IV/1, 1065. 
re expresamente a las causas matrimoniales ${ }^{31}$. Precisamente este "olvido" del MIDI, confirma la vigencia en este punto de la Dignitas connubii, provocando la actualidad de lo establecido en 2005, acerca de la misión que deben desarrollar los abogados estables y la que corresponde a los que están admitidos en el elenco del tribunal, una adaptación que además ahora parece hacerse más necesaria a la vista de la institución de la investigación prejudicial, y del deseo de que las causas matrimoniales no resulten onerosas para los que quieran proponerla o para quien se vea demandado. Convendría dibujar bien el perfil de ambas figuras, partiendo de que en los dos casos se trata de la intervención en estos procesos de letrados expertos en Derecho Canónico, profesionales sin los cuáles no es posible que se lleve a cabo un procedimiento judicial y, no hay que olvidar que la reforma del papa Francisco se fundamenta en la naturaleza judicial del procedimiento para declarar la nulidad matrimonial ${ }^{32}$. En cualquier caso, hay que plantear la posibilidad de que sean abogados quienes realicen la investigación prejudicial que se define en las Reglas Procedimentales del MIDI. Veremos hasta qué punto esto es factible y conveniente, o no.

En otros casos se indica que esta investigación pastoral se encarga a los Centros diocesanos de Orientación Familiar, habitualmente conocidos por sus siglas COF. Estos centros reúnen a profesionales o expertos en diversas disciplinas relacionadas con la vida familiar (psicólogos, pedagogos, médicos, juristas, etc.) que atienden a quienes se acercan a pedir consejo y organizan actividades de promoción o campañas de divulgación de cuestiones de interés para las familias. El Directorio de Pastoral Familiar elaborado por la Conferencia Episcopal Española los señala como colaboradores con el Tribunal en determinadas cuestiones: en primer lugar como el órgano adecuado para llevar a cabo el intento de reconciliación de los matrimonios que plantean la nulidad ${ }^{33}$,

$31 \ll$ En la medida de lo posible, en todo tribunal ha de haber patronos estables, que reciban sus honorarios del mismo tribunal, y que ejerzan la función de abogado o de procurador, sobre todo en las causas matrimoniales, en favor de las partes que libremente prefieran designarlos» (c. 1490 CIC).

32 «Quod fecimus vestigia utique prementes Decessorum Nostrorum, volentium causas nullitatis matrimonii via iudiciali pertractari, haud vero administrativa, non eo quod rei natura id imponat, sed potius postulatio urgeat veritatis sacri vinculi quam maxime tuendae: quod sane praestant ordinis iudiciarii cautiones», FrancISCO, Motu Proprio Mitis Iudex Dominus Iesus, AAS CVII (2015) 959.

33 «[A] un cuando existan razones legítimas en orden a iniciar un proceso de separación, nulidad matrimonial, disolución del matrimonio en favor de la fe o dispensa del matrimonio rato y no consumado, antes de aceptar la causa, el juez, o por delegación el Centro de Orientación Familiar, empleará medios pastorales (Orientación Familiar) tendentes a la reconciliación de las partes. De ahí la importante necesidad de la coordinación de los Tribunales Eclesiásticos con los Centros de Orientación Familiar», CONFERENCIA EPISCOPAl EspaÑola, Directorio de Pastoral Familiar, n. 210. 
por otra parte se deben encargar de informar a quienes han decidido plantearla sobre las características del proceso de nulidad y lo que significa ${ }^{34}$, también pueden desarrollar un papel en el caso de levantamiento del vetitum para pasar a unas nuevas nupcias ${ }^{35}$. Por último, este documento señala que estos Centros pueden colaborar con los tribunales eclesiásticos aportando pruebas a los pro$\operatorname{cesos}^{36}$. Ciertamente varias de estas tareas pueden relacionarse con la investigación prejudicial o pastoral del MIDI.

Sólo uno de los tribunales de los que ha contestado a la encuesta explica que esa investigación prejudicial la realiza un sacerdote colaborador de la Vicaría judicial. Me consta que algunas diócesis pueden contar con personas que, tras jubilarse en el tribunal, han decidido hacerse cargo de este tipo de tarea cuando se las han encomendado. En todo caso carecen entonces de la condición de miembros del tribunal. Sin embargo, la doctrina se ha planteado la posibilidad de que miembros del tribunal se hagan cargo de la investigación prejudicial. Ros Córcoles afirma que nada obsta a que el Vicario judicial sea el que realice esa investigación, al menos para los casos de proceso brevior, pues su misión se limita a dictaminar el seguir el proceso y nombrar a instructor y asesor ${ }^{37}$, mientras que Gerardo Núñez opina, invocando el art. 113, 2 de la Dignitas connubii que podría dar la sensación, si se involucra el Vicario judicial (u otros jueces del tribunal) en la investigación prejudicial, que esta causa está avalada por el Vicario, o por el juez que ha intervenido ${ }^{38}$. Se está considerando como solución que el tribunal cuente con una persona encargada de estas investigaciones prejudiciales.

En consecuencia, parece que la práctica nos presenta estas tres opciones: que sean los letrados colaboradores del tribunal, los COF, o unas personas de-

34 «En el caso de que, convencidos, y tras la pertinente orientación familiar, estén decididos a acudir a los Tribunales Eclesiásticos (...) conviene que el asesoramiento jurídico sea ejercido por profesionales verdaderamente católicos que puedan explicar no sólo los procedimientos sino el sentido de los mismos, y hacer presente a la Iglesia en esa situación conflictiva. De ahí la importante necesidad, también en esta ocasión, de la coordinación de los Tribunales Eclesiásticos con los COF», Conferencia Episcopal Española, Directorio de Pastoral Familiar, n. 213.

35 «n los procedimientos de levantamiento de veto para contraer nuevas nupcias tras una declaración de nulidad, los Tribunales Eclesiásticos podrán recurrir también a los COF para solicitar de ellos los pertinentes informes periciales (psicológicos, espirituales, etc.)», CONFERENCIA EPISCOPAl ESPaÑola, Directorio de Pastoral Familiar, n. 213.

36 Conferencia Episcopal Española, Directorio de Pastoral Familiar, n. 277. También podrá ejercer una función pericial en relación a los Tribunales eclesiásticos.

37 J. Ros Corcoles, El Vicario judicial y el instructor en los procesos de nulidad matrimonial tras el Motu Proprio Mitis Iudex, Ius Canonicum 56 (2016) 98. En este caso de pasar la causa al proceso ordinario el Vicario que hubiese hecho la investigación no podría actuar como juez en el turno.

38 G. NúÑEZ, La fase..., cit., 32. 
terminadas por el tribunal eclesiástico quienes se hagan cargo de la investigación prejudicial o pastoral mencionada en los artículos del 2 al 5 de las Reglas de Procedimiento del MIDI.

\subsection{Quiénes pueden solicitarla}

Otra cuestión práctica que convendría analizar es quiénes son los sujetos de estas investigaciones, quiénes son las personas que directa o indirectamente van a solicitar que se realicen. No tenemos datos de las características de quienes se han acercado a los tribunales solicitando información acerca de los procesos de nulidad. Sí que se ha constatado, con los datos de la encuesta, un aumento extraordinario del número de ellas en los días en que se conoció la reforma, que como se recordará fue muy difundida por todos los medios de comunicación. Independientemente de la labor de información que asumen los tribunales eclesiásticos que pueden solicitar todos los fieles, si nos estamos ciñendo a las normas canónicas del MIDI, y por extensión también a las de las Reglas de Procedimiento, el art. 2 se refiere concretamente a los «fieles separados o divorciados que dudan sobre la validez del propio matrimonio o están convencidos de su nulidad».

En primer lugar, los términos que usa la norma no dejan lugar a dudas de que estas investigaciones se llevan a cabo en casos de fieles ya separados o divorciados ${ }^{39}$, por tanto, no se trata de matrimonios en los que se detectan problemas, sino casos en los que ya se ha interrumpido la convivencia matrimonial ${ }^{40}$. Se tratará siempre de matrimonios que de algún modo se presentan ya rotos, y aunque nunca hay que olvidar plantear la posibilidad de reconciliación a los cónyuges que establece en los cánones 1676 y 1685 de Código, en estos casos habitualmente será muy difícil.

No hay que descartar que haya casos de matrimonios rotos entre personas que no están dispuestas a abandonar su fe y la práctica religiosa, hay que pensar que quienes tienen esta buena disposición acudirán a asesorarse habi-

39 Así lo ha señalado C. M. FABRIS, Indagine pregiudiziale..., cit., 488.

40 En este punto se ha restringido el ámbito de actuación que se contemplaba al concluir el Sínodo de la familia y que entendía este servicio también para matrimonios en crisis: «Será por lo tanto necesario poner a disposición de las personas separadas o de las parejas en crisis, un servicio de información, de asesoría y de mediación, vinculado con la pastoral familiar, que podrá también acoger a las personas con ocasión de la investigación preliminar al proceso matrimonial» (SíNODO DE LA FAMILIA, Relatio finalis, n. 82). 
tualmente al párroco o incluso directamente a los COF de la diócesis, y así conocer si existen indicios de que su matrimonio sea nulo. Pero no son éstos los casos más frecuentes. Generalmente los casos son de personas que, habiendo contraído en su día matrimonio ante la Iglesia, decidieron romperlo ante determinadas dificultades, acudiendo a las leyes civiles. Esta situación les ha alejado, si no lo estaban ya, de la Iglesia. Estas personas pueden, tiempo después, querer contraer matrimonio de nuevo y eligen para ello a una persona católica para la cual sí es importante contraer un matrimonio sacramental. Indagar sobre el matrimonio canónico que aquella persona contrajo, sobre las circunstancias en las que se celebró y las causas de su fracaso, puede dar luz sobre la posibilidad de plantar un proceso de nulidad o ser inicio de una fase de discernimiento acerca de la propia situación. Algo parecido sucede en los casos de los separados, divorciados civilmente y ya vinculados en una nueva unión; personas que contrajeron matrimonio canónico, que en su momento recurrieron al divorcio y después a una nueva unión, en este caso civil, en la que han formado una familia, y que, por alguna razón, muchas veces al hilo del nacimiento de un hijo, se acercan de nuevo a la Iglesia con intención de volver a la comunión con ella. También en este caso, la investigación sobre los primeros matrimonios de estas personas podrá aportar indicios acerca de una posible causa de nulidad o sentar las bases de un proceso de acercamiento a la Iglesia considerando todas las opciones que cabrían, dado que es un hecho ya esa segunda unión ${ }^{41}$. Creo que éstos serían los casos típicos en los que cabe aplicar esas investigaciones prejudiciales o pastorales.

\subsection{Sus características}

Volviendo de nuevo al texto de las Reglas de Procedimiento que regulan la investigación prejudicial o pastoral, intentando desentrañar el sentido con el que se emplea en ella el término "investigación", comprobamos que son seis las ocasiones en las que se menciona esta palabra:

1. La investigación acoge dentro de las estructuras parroquiales o diocesanas a los fieles separados o divorciados, para conocer su condición y recoger elementos útiles para una eventual celebración de un proceso judicial ordinario o brevior.

\footnotetext{
${ }^{41}$ Me estoy refiriendo a los que resultan de la aplicación del art. VIII de la Amoris Laetitia.
} 
2. Debe estar integrada en una pastoral matrimonial diocesana unitaria.

3. Es confiada por el obispo a personas idóneas, no exclusivamente con competencias jurídico-canónicas.

4. Puede organizarse mediante una estructura estable y en cooperación con otras diócesis para desarrollarla mejor (vademécum).

5. Recoge elementos para introducir la causa, por parte de los cónyuges o de su patrono, e indaga si están ambos de acuerdo.

6. Concluye en la demanda a presentar, si fuera el caso.

Además, una vez se usa el término "investigación" en la nueva redacción del Código, en el c. 1683, 2, cuando se señala que se podrán plantear como causas a tramitar por el procedimiento más breve ante el obispo: aquellas que no requieran una investigación o una instrucción más precisa, o sea cuando la investigación prejudicial realizada siguiendo las pautas anteriores se entienda (a juicio del Vicario) suficiente a la vista de los datos recopilados y las pruebas con las que tras ésta se cuenta.

A la vista de las seis primeras premisas, considerándolas como características, se puede intentar una definición de lo que sea esta investigación prejudicial; al hilo de la mención en el canon, se puede relacionar ésta con el procedimiento más breve.

\subsubsection{Acogida conforme a la pastoral matrimonial}

Este proceso de investigación no puede ser de inquisición, sino de acogida. Se trata por tanto de un instrumento de integración en las estructuras eclesiales (habitualmente en la parroquia), de estas parejas que han formado una familia partiendo de un matrimonio no válido. Esta acogida se hace con la finalidad de profundizar en el conocimiento de la realidad de estas personas con la idea última de conducirles a una comunión con la Iglesia que ellos realmente desean, de modo que debe estar contemplada dentro de la pastoral diocesana, y en consecuencia en la de cada parroquia. Sucede a menudo que estas parejas, en situación irregular, contactan con la parroquia en momentos concretos (catequesis de los hijos, enfermedad, actos de cofradías a las que se pertenece por tradición familiar, etc.), y debe estar prevista la forma para que, a partir de estos contactos, puedan ser acogidos y en su caso soliciten que se hagan estas indagaciones acerca de su situación familiar, con objeto de detectar eventualmente alguna causa de nulidad en el matrimonio fracasado. 
Quizá no haya sido buena idea llamar a la investigación prejudicial o pastoral, usando para denominarla estos dos términos y señalando además a ambos como equivalentes ${ }^{42}$. Si se realiza, como queda establecido, en el ámbito de "la pastoral matrimonial diocesana unitaria", es lógico que se llame pastoral. Pero al decirse que también puede denominarse prejudicial, parece darse a entender que lo judicial está dentro del marco de la pastoral y ¿es esto exactamente así? Arroba Conde ha hablado de una acción pastoral especializada que denomina pastoral judicial ${ }^{43}$. Que dentro del munus del obispo que es pastoral, se incluye la potestad judicial que debe ejercer en las causas matrimoniales, como recuerda constantemente el papa Francisco, no hay duda. Pero no se puede obviar que el proceso judicial se caracteriza por la existencia del "contradictorio", y por la aplicación en él de las garantías procesales, especialmente los derechos de igualdad y de defensa de las partes y el derecho de apelación. Se podría entender que las indagaciones que se hagan a partir de la pastoral familiar lleguen a convertirse en investigación prejudicial, pero eso será sólo si se encuentran indicios de nulidad matrimonial. No obstante, hay una serie de precauciones que habrán de tomarse para el caso de que la investigación derive a prejudicial, a riesgo si no de desvirtuar el uso posterior del proceso, y en consecuencia no aplicarlo con justicia. Por ejemplo, habrá que tomar precauciones con respecto a quién lo va a llevar a cabo. De ser una acción meramente pastoral, no tendría relevancia que la llevara a cabo un miembro del tribunal, o el mismo obispo. Pero ante la posibilidad de que algunos de ellos puedan llegar a ser los encargados de emitir un veredicto sobre el matrimonio si se plantea la causa de nulidad, a riesgo con esto de quebrar la igualdad de las partes, hay que entender que los miembros del tribunal o el obispo no puedan ser personas adecuadas para efectuar estas investigaciones.

\subsubsection{Confiada por el obispo}

La elección del encargado de esta investigación es algo importante, por ello su designación corresponde al obispo (el texto dice "ordinario del lugar"), que es al mismo tiempo pastor y quien tiene la potestad de administrar la justicia en su diócesis. No se trata de que cada persona pueda escoger a alguien

\footnotetext{
Así lo ponen de manifiesto F. J. REgordán, La investigación..., cit., 41; P. A. Moreno, El servicio..., cit., 67. Este último autor ofrece dos razones para inclinarse por el uso del calificativo «prejudicial».

${ }^{43}$ M. ArRoba Conde, La pastoral judicial..., cit., 70 y ss.
} 
que realice esa investigación. La expresión que se usa en la norma es «se confía por el obispo». ¿Quiénes sería estas personas idóneas? Las Reglas procedimentales sólo señalan como requisito: no tendrán competencia jurídico-canónica exclusivamente ${ }^{44}$. A continuación, se indica que de modo preferente se designa al párroco propio o aquel que los preparó para el matrimonio, en segundo término lo harán otros clérigos, consagrados o laicos, que tengan la aprobación del ordinario del lugar. Hay que entender, pues, que siempre que el párroco actúe como tal no necesitará una autorización previa y específica del obispo para realizar esta investigación ${ }^{45}$.

Del texto de este artículo se deduce que el párroco goza de esa confianza del obispo para llevar a cabo la tarea de esta investigación, bien sea el del lugar donde vive el solicitante en el momento en el que requiere de la investigación o bien sea el del lugar donde vivía en la época en la que se preparaba para el matrimonio ${ }^{46}$. Creo que la idea que subyace en estas disposiciones es intentar que las personas que dudan acerca de su situación matrimonial tengan otra opción diferente a la de acudir al tribunal eclesiástico. Y esta idea es buena. En primer lugar porque el tribunal no es un órgano adecuado para este tipo de consultas, precisamente por ser el encargado por el obispo para decidir, tras un proceso judicial, si el matrimonio fue válido o no; y en segundo lugar porque no siempre plantear la causa de nulidad será la solución y en caso de que no haya indicios que aconsejen plantearla, sólo en el ámbito de la pastoral se podrá llevar a cabo con estas personas un acompañamiento que les ayude a comprender y acepta su situación en la Iglesia ${ }^{47}$.

${ }^{44}$ Dice el art. $3 \mathrm{RP}$ «...dotadas de competencias no sólo exclusivamente jurídico-canónicas». El Subsidio Aplicativo dice «dotadas de competencias incluso no exclusivamente jurídico-canónicas», 15.

45 Así también C. M. FABRIS, Indagine pregiudiziale..., cit., 492.

${ }^{46}$ Ciertamente la determinación de quiénes son el párroco propio o el párroco que los preparó para el matrimonio puede presentar alguna dificultad, C. M. FABRIS, Indagine pregiudiziale..., cit., 492-493. Sin embargo, entiendo decisivo que se trata del párroco al que acuda el solicitante, siempre que en efecto lo sea en alguno de los dos sentidos que recoge la norma. No entiendo que se trate de un acto administrativo. Tratándose de cuestiones que afectan a la intimidad de las personas este margen de elección facilita ese primer acercamiento.

47 En este sentido quiero comentar que en el Reglamento del Tribunal Diocesano de Huelva se introdujo esta prescripción: «Art. 13. Cuando, en un proceso matrimonial se dicte sentencia declarando no consta la nulidad o se deniegue por la Santa Sede la gracia de la disolución, la parte dispositiva de la resolución será comunicada a la Delegación Diocesana para la Familia a los solos efectos de procurar o facilitar el acompañamiento pastoral de las personas implicadas, en particular quienes han visto defraudada su aspiración a verse libres del vínculo conyugal». Este reglamento fue remitido a la Signatura Apostólica a efectos meramente informativos, y allí repararon que el contenido de este artículo podría contravenir los principios de confidencialidad sancionados por el ordenamiento canónico. 
En este punto hay que constatar que si bien los documentos de la III Asamblea Extraordinaria del Sínodo, que se celebra en octubre de 2014, se menciona expresamente el art. 113 de la Dignitas connubii al referirse a este servicio de asesoramiento ${ }^{48}$, en el Instrumentum Laboris de la XIV Asamblea Ordinaria, de junio de $2015^{49}$ la propuesta ya no se menciona. La Relación final de esta Asamblea, que se da a conocer el 24 de octubre de 2015, tampoco se refiere al precepto de la Dignitas connubii, pues menciona ya lo establecido en el MIDI, promulgado el mes anterior ${ }^{50}$. Entiendo que conforme se iba profundizando en el sentido del discernimiento y el acompañamiento pastoral que se propone para estas personas separadas o divorciadas, más se hacía patente la necesidad de separar estas tareas de las que desarrollan jueces y abogados en los procesos matrimoniales.

Creo que éstas son las razones que justifican el que se pretenda separar la función de consulta de las tareas que habitualmente viene realizando el tribunal eclesiástico, con la colaboración de los abogados del elenco. Entiendo que estos servicios de consulta, vinculados al tribunal, deben seguir ejerciendo las labores de asesoría técnico-jurídica para todos los que lo soliciten ${ }^{51}$, así como encargarse de proveer de patronos estables ${ }^{52}$, pero sus miembros (que serán cargos del tribunal o abogados en ejercicio) no deben involucrarse en la realización de estas investigaciones prejudiciales ${ }^{53}$.

48 «Exige resaltar la responsabilidad del Obispo diocesano, quien en su diócesis podría encargar a consultores debidamente preparados que aconsejaran gratuitamente a las partes acerca de la validez de su matrimonio. Dicha función puede ser desempeñada por una oficina o por personas calificadas (cfr. Dignitas connubii, art. 113, 1)», SíNODO DE LOS OBISPOS, III Asamblea general extraordinaria. Los desafíos pastorales de la familia en el contexto de la evangelización, Relatio Synodi, 18 de octubre de 2014, n. 49.

49 «Se propone que en cada Diócesis se garanticen, de manera gratuita, los servicios de información, asesoramiento y mediación relacionados con la pastoral familiar, especialmente a disposición de personas separadas o de parejas en crisis. Un servicio así cualificado ayudaría a las personas a emprender el recorrido judicial, que en la historia de la Iglesia resulta ser el camino de discernimiento más acreditado para verificar la validez real del matrimonio», SíNODO DE LOS OBISPOS, XIV Asamblea General Ordinaria. La vocación y la misión de la familia en la Iglesia y en el mundo contemporáneo, Instrumentum Laboris, junio 2015, n. 117.

50 SínOdo DE LOS OBISPOS, XIV Asamblea General Ordinaria. La vocación y la misión de la familia en la Iglesia y en el mundo contemporáneo, Relación Final, octubre 2015, n. 82.

${ }^{51}$ En otro sentido, sobre la pervivencia de esos servicios de asistencia se ha escrito: «consideramos que el Mitis Iudex no pretende anular dicho servicio sino ampliarlo, involucrando un mayor número de agentes pastorales a diversos niveles». P. A. MORENO, El servicio..., cit., 69.

52 C. 1490 CIC.

${ }^{53}$ Si estas personas dejaran de pertenecer al tribunal o de ejercer la abogacía, seguramente sí que podrían solicitar incorporarse al grupo de los designados para efectuar estas investigaciones. 
Muy en segundo lugar puede haber pesado a la hora de tomar esta decisión el que para la mayoría de los fieles la idea de acudir a un tribunal eclesiástico se plantea como algo extraordinario. De entrada, los tribunales se encuentran en las sedes episcopales, de modo que existe una primera distancia física, pero no es sólo ésa, también hay que considerar esa "distancia moral", que cohíbe a los ajenos al mundo del derecho a acercarse a ellos.

La importancia que a la luz de las nuevas normas procesales tiene el párroco es paralela a la que se le ha dado al papel del obispo en la reforma ${ }^{54}$. Así lo pone de manifiesto el papa Francisco cuando se dirige a un grupo de párrocos que asistían a un curso organizado en febrero de 2017 por el Tribunal de la Rota para profundizar en el conocimiento del MIDI ${ }^{55}$, a ellos les corresponderá en primera instancia asistir a quienes quieran clarificar la situación de su matrimonio, poniéndoles en contacto en su caso con quienes en un segundo momento les podrán asesorar cara a plantear su nulidad.

Pero consciente de que el párroco puede no contar con el tiempo que requiere esta investigación y con las herramientas precisas, se prevé que haya otras personas que puedan desarrollar esta tarea. ¿Qué competencias deben poseer las personas para obtener la aprobación del obispo para poder llevar a cabo estas investigaciones? ¿Se trata de una designación ad casum o de una habilitación general? El hecho de que se señale ya como idóneo al párroco viene a ofrecer un perfil de la persona que podrá estar capacitada para esta tarea y, por el contrario, que se desdeñe a quienes sólo tienen competencias jurídico-canónicas, descarta que sean letrados los que la realicen. El legislador se inclina por habilitar a una persona que ofrezca confianza, que tenga unos conocimientos generales sobre las materias a dilucidar y que conozca también el ambiente en el que se desarrolla actualmente la vida de éstas.

A partir de ahí cada obispo sopesará la formación y las capacidades de las personas con las que puede contar, teniendo en cuenta que, si forman parte del

${ }^{54}$ Es más, si se lee con detenimiento el art. 1 de las Reglas de Procedimiento, no pasa desapercibido el detalle de que es el obispo el que comparte con los párrocos la solicitud pastoral hacia los cónyuges separados y divorciados, y no viceversa.

55 «En la mayor parte de los casos sois los primeros interlocutores de los jóvenes que desean formar una nueva familia y casarse por el sacramento del matrimonio. Y también se dirigen a vosotros esos cónyuges que, a causa de serios problemas en su relación, se encuentran en crisis, necesitan reavivar la fe y redescubrir la gracia del sacramento; y en ciertos casos piden indicaciones para iniciar un proceso de nulidad. Nadie mejor que vosotros conoce y está en contacto con la realidad del tejido social en el territorio». L'Osservatore Romano (ed. en español), n. 9, 3 de marzo de 2017, 3; Ecclesia, n. 3876, 25 de marzo de 2017, 441-442; Communicationes XLIX (2017) 51-53. 
tribunal, o del elenco de abogados, no debieran asumir ese papel, en este caso por motivos de ética profesional. Las personas que trabajan en los COF pueden presentar en ocasiones un perfil adecuado, y eso ha de tenerse en cuenta, pero entiendo que la norma habla de personas con capacidad aprobada por el ordinario local ${ }^{56} \mathrm{y}$ por tanto no parece correcto que sean los COF, como institución quienes asuman esta misión.

No está claro si, una vez la persona está habilitada por el obispo, debe ser designada por él cada vez que actúe o si es el párroco quien debe escoger a alguna entre el grupo de las autorizadas por el obispo, en el caso de que no pueda asumir el mismo la investigación. En principio parece más lógica la segunda opción. El obispo puede hacer una delegación general en el párroco para que éste designe a una persona concreta. Sí que convendrá que el encargo se materialice en un escrito, firmado y que recoja las correspondientes cláusulas de confidencialidad.

Sin embargo, el resumen que con relación al tema del servicio jurídicopastoral, ofrece el Subsidio aplicativo no concuerda con lo estipulado en la norma que lo regula y que he venido comentando. La síntesis con la que concluyen las páginas que le dedica se limita a decir:

«En el ámbito de la pastoral matrimonial diocesana deben ser identificadas personas idóneas que puedan: ayudar a superar las crisis conyugales; recoger los elementos útiles para la causa de nulidad; confeccionar el escrito de demanda para presentar ante el tribunal ${ }^{57} \gg$.

Creo que, si nos atenemos a lo establecido en la norma, tal como hemos ido analizando, hay que colegir que:

1. No se trata de un servicio de ayuda a las crisis matrimoniales sino de un servicio de ayuda para clarificar la situación de los fieles que tras un fracaso matrimonial quieren permanecer o retornar a la comunión con la Iglesia.

2. No se trata de identificar a personas capaces de realizar estas funciones, sino de que existan personas designadas por el obispo para hacerlas.

56 «Puesto que se trata de indagar en cuestiones delicadas, conviene que la persona responsable de la investigación prejudicial sea una sola, actuando bajo juramento de preservar el secreto profesional, esa persona responsable podrá, con consentimiento del solicitante, pedir la colaboración de las personas que considere oportunas para llevar a cabo esta labor». P. A. MORENO, El servicio..., cit., 74.

57 Subsidio Aplicativo, 16. 
3. La investigación que prestaría el servicio no tiene como fin recoger elementos útiles para la causa de nulidad, sino indagar si hubiera indicios de nulidad.

4. No tienen por qué ser personas idóneas para confeccionar un escrito de demanda, tarea que deberá desarrollar una persona con formación jurídico-canónica (precisamente la cualidad que no se exige como regla general para ser designado para llevar a cabo las investigaciones pastorales), en el entendido de que sólo una demanda bien elaborada puede dar lugar a un proceso rápido y con garantías, ya sea ordinario o brevior.

\subsubsection{Estructuras para proveer el servicio jurídico-pastoral}

El segundo párrafo del art. 3 de las Reglas de Procedimiento deja previsto que la diócesis por si misma o junto a otras puede «constituir una estructura estable a través de la cual proveer a este servicio». No se trata de instituir una estructura para prestar el servicio de apoyo jurídico-pastoral sino para proveerlo de personas capacitadas para ejercitarlo. En este sentido cabría pensar para nuestro país en una adecuación de los COF, para que pudieran impartir formación especial a quienes quieran colaborar en esta tarea y encargarse de estas investigaciones pastorales, tras ser designado para ello por el obispo. También, y siempre a la vista de las necesidades y los medios de cada diócesis, cabe que haya una estructura que ayude a los párrocos a tener formación en estas tareas. En este punto se sugiere la elaboración de un vademécum. El Subsidio Aplicativo dice que la tarea de elaborar este u otros vademécum corresponde a la Conferencia episcopal, pero aparte de esta asignación, no queda claro cuál es el objetivo de estos documentos:

«Según la nueva ley, las Conferencias episcopales organizarán un vademécum para garantizar la organización y la uniformidad de los procedimientos, con particular atención al desarrollo de la investigación pastoral $\gg^{58}$.

En efecto, no se concreta si el contenido de este documento versaría sobre la forma de hacer las investigaciones previas (fases, documentos a comple-

58 Subsidio Aplicativo, 10-11. 
tar, preguntas que hacer, temas que abordar, etc.) o debe tratar sobre la forma en la que se estructura su organización (forma de solicitarla, designación de quien las realiza, formación que se requiere, obligación de secreto, relación con abogados...). Me inclino a pensar que se refiera a lo segundo, pues la forma en la que se deba llevar a cabo estas investigaciones será muy diferente en cada caso, dependerá de muchos factores y difícilmente habrá un modelo general. Se ha hablado de la conveniencia de elaborar un cuestionario a seguir en el desarrollo de esas investigaciones, pero esa solución que puede ser útil en los servicios de asistencia jurídica que se prestan en los Tribunales, sin embargo, difícilmente se adaptan a las situaciones tan diferentes que se pueden presentar ante el párroco ${ }^{59}$.

La experiencia nos muestra gran variedad entre las personas divorciadas que solicitan investigación de su matrimonio, ante la sospecha de que al contraerlo se hubiese dado una causa de nulidad. Con frecuencia se trata de matrimonios rotos hace muchos años; a menudo, fueron matrimonios breves, algunos celebrados en lugares distantes de la residencia actual de la persona; también es frecuente que la otra persona no quiera recordar nada de lo sucedido, que no colabore. Con todo esto la tarea de quien lleva la investigación a menudo no consiste sólo en recabar datos, también comprende la de convencer a unos y otros acerca de la utilidad de todo ese proceso. $Y$ en su caso informarles de cómo se lleva a cabo el proceso judicial, con cuidado de explicarles los derechos y deberes que se ejercitan en él. En suma, se trata de un proceso largo y a menudo intrincado, en el que difícilmente se puede seguir un guion predeterminado, aunque sí debe tener una finalidad clara y dotar a las personas de formación adecuada.

\subsubsection{Fines}

$\mathrm{Si}$, como puede suceder, hubiera indicios de nulidad ¿cómo se debe actuar? Lo primero y principal es ser consciente de que en ningún caso los resultados de la investigación pastoral van a concluir por si solos que existió un matrimonio nulo. Es más, creo que siempre se debe advertir, expresamente y por escrito, que en ningún caso la opinión de quien realice la investigación prejudicial, por fundada que esté, es vinculante para el tribunal que examine y

59 Vid. P. A. Moreno, El servicio..., cit., 80; E. DE LeÓN ReY, La tramitación..., cit. 
decida la causa. Por eso es importante destacar que durante la investigación sólo se recogen los "elementos" que dan indicios de nulidad. La prueba se practicará en el momento procesal adecuado y de acuerdo con las reglas que la regulan. Deberán ser entonces apreciadas por el juez y sin intervención de quien ha dirigido la investigación prejudicial. Estos elementos, indicios de nulidad, como explica el art. 4 de las Reglas de Procedimiento, deben ponerse en manos de quienes tienen la legitimidad para interponer la nulidad, para que ellos directamente, o como será más frecuente, sus representantes legales, planteen la causa de nulidad ${ }^{60}$, pero cualquier memorial hecho con este fin no deja de ser un documento privado ${ }^{61}$.

En este mismo artículo se señala algo muy concreto que se debe hacer durante esta investigación: indagar si ambas partes están de acuerdo en pedir la nulidad. Al recogerse expresamente esta cuestión en las Reglas de Procedimiento que regulan la investigación prejudicial se está relacionando, indirectamente al menos, a ésta con el procedimiento brevior, pues es bien sabido que sólo si ambos cónyuges firman la demanda el proceso podrá sustanciarse de este modo. Esto añade una dificultad más a esta investigación pues, aun cuando la otra parte no esté interesada en plantear la nulidad, deberá ser oída por el responsable de la investigación, sólo sea por comprobar si está de acuerdo o no con la demanda.

Pero la persona que se encarga de la investigación ¿debe buscar el consenso de las partes en orden a acusar la nulidad del matrimonio? Podría pensarse que es así a la vista de esta referencia expresa a indagar «sobre si ambos están de acuerdo en pedir la nulidad». Si pensamos en el adjetivo "pastoral" que califica a esta investigación, hay que concluir que en ningún caso se debe favorecer la confrontación entre aquellos que un día contrajeron matrimonio. El ejercicio de la misericordia nunca debe olvidarse, tampoco cuando se trata de practicar la justicia. El contradictorio procesal, que es un medio que con-

${ }^{60}$ Vid. M. ARRoBa Conde, La pastoral judicial y la preparación de la causa en el motu proprio Mitis Iudex Dominus Iesus, en M. E. Olmos (ed.), Procesos de nulidad matrimonial tras la reforma del Papa Francisco, Dykinson, Madrid 2016.

61 «Como sucede con los memoriales escritos por las partes que ya hoy se adjuntan a las demandas, se tratará de declaraciones que forman parte de los "acta" pero no de los "probata" ». M. ARROBA CONDE, La pastoral judicial..., cit., 76. Sobre adjuntar memoriales a la demanda vid. Respuesta del Pontificio Consejo para los Textos Legislativos de 23 de febrero de 2017. Prot. N. 15720/2017. http://www.delegumtextibus.va/content/testilegislativi/it/risposte-particolari/procedure-per-ladichiarazione-della-nullita-matrimoniale.html (consultado por última vez el 28 de marzo de 2018). 
tribuye al esclarecimiento de la verdad, no debe convertirse en un arma de contienda entre las partes. Pero al mismo tiempo, para nada puede ser admisible que quien se encargue de esta fase de indagación intente siquiera amañar un acuerdo entre las partes que favorezca la declaración de nulidad. En orden a saber si estarían ambas partes de acuerdo en solicitar la nulidad, lo que hay que comprobar es que los dos admiten los hechos ocurridos y las circunstancias en las que contrajeron matrimonio y en segundo lugar si ambos admiten que la Iglesia juzgue sobre esos hechos y circunstancias.

\subsubsection{Conclusión con la demanda}

Por último, las Reglas de Procedimiento indican que la investigación prejudicial «se concluye con la demanda». En el Subsidio Aplicativo se lee «la investigación concluye con la redacción de la petición y/o del escrito de demanda, para presentar, si fuera el caso, al juez competente» ${ }^{62}$. Sin entrar en la cuestión de cuál pudiese ser la diferencia entre la petición o el escrito de demanda ${ }^{63}$, parece que no cabe otra opción para concluir esta fase que el paso a la vía judicial, sin embargo, resulta lógico que tuviese que quedar prevista la forma de conclusión de estas investigaciones cuando, tras las realizarlas, no se aprecien indicios de nulidad. No hay que olvidar que se trata de una investigación pastoral y no se podrá dejar sin solución la situación de estas personas en relación con la comunidad eclesial. Al menos debería quedar previsto dotar de alguna utilidad a los resultados de esta investigación en orden a discernir el futuro de la nueva unión en que viven.

Quizá el hecho de que nos encontremos ante unas reglas de procesales, dictadas por tanto con la finalidad de seguir un proceso judicial, justifica esta falta de previsión, que quedaría suplida en tanto la investigación se ha realizado dentro de la pastoral de matrimonio diocesana. Es de imaginar que quienes realizan la investigación previa estén al tanto de las distintas vías previstas dentro de la pastoral para estos casos de uniones irregulares.

En cualquier caso, quizá hubiese sido preferible no señalar tan tajantemente la demanda como resultado final de la investigación y hubiera sido más conveniente que ésta concluyera con algún tipo de informe que se trasladaría,

62 Subsidio Aplicativo, 15.

${ }^{63}$ C. M. FABRIS, Indagine pregiudiziale..., cit., 499. Ha querido ver una relación del término "petición" con lo establecido en el c. 1683 para la solicitud del proceso brevior. 
si las partes lo quieren, a una persona con formación específicamente jurídica, un letrado especialista, que daría forma a la solicitud y la presentaría ante un tribunal competente ${ }^{64}$. Se acabaría de este modo la fase prejudicial para comenzar la judicial. Lo que debe quedar claro es que la tarea de quien hace la investigación no suple la de la asistencia técnica jurídica que es fundamental en el proceso, y que la fase previa es esencialmente pastoral, y para nada judicial. De modo que su eventual fracaso, o el hecho de que nunca se concluyan, no tiene las consecuencias que podría tener el desistir de una causa, o su caducidad.

\subsection{Una definición práctica}

A la vista de las características de la investigación prejudicial o pastoral que se desprenden de las normas vigentes y de la praxis que hasta el momento he podido analizar, se podría decir que, de acuerdo con lo establecido en el MIDI, las personas separadas o divorciadas pueden solicitar al párroco del lugar donde viven, o aquel que en su día los preparó para el matrimonio, que él mismo o una persona entre las habilitadas por el obispado para ello, se interese por su situación y analice las circunstancias en las que contrajo el matrimonio canónico que fracasó. Con este fin la persona encargada se entrevistará con ambos cónyuges y con otras personas, especialmente con quienes los prepararon para el matrimonio en la Iglesia. La persona encargada de esta investigación se compromete a informar sobre la investigación realizada a quien la solicitó y en caso de que haya indicios de nulidad, le comunicará los datos que ha encontrado y que pueden contribuir a plantear la causa. Asimismo, se compromete a informar en este caso al otro cónyuge y averiguar si está o no de acuerdo en solicitar la nulidad del matrimonio.

En este punto, informará además a ambos sobre el desarrollo de los procesos de nulidad y de la forma en la que pueden acceder a un asesoramiento legal específico, de los costes del proceso, de los honorarios de los abogados, $\mathrm{y}$ de las posibilidades de ver reducidas las tasas y los honorarios.

En caso de no haber indicios de nulidad, con el consentimiento de quien ha solicitado la investigación previa, se pondrán los resultados de ésta en conocimiento del párroco del lugar donde actualmente viva (si no ha sido él

${ }^{64}$ Sobre el papel institucional del abogado en las causas matrimoniales tras la reforma del MIDI, M. ARroba Conde, La pastoral judicial..., cit., 76-82. 
quien haya hecho esa investigación), para que éste pueda acompañarlos en su intención de participar, aun desde su estado, en la vida de la Iglesia ${ }^{65}$.

\section{LA INVESTIGACIÓN PREJUDICIAL Y EL PROCESO BREVIOR}

Como indiqué antes, sólo en una ocasión entre los cánones reformados en 2015 se menciona la palabra investigación ${ }^{66}$, al señalar, como uno de los requisitos para que se siga el proceso brevior, el que no sea necesaria "más investigación". Con esto se pone de manifiesto que los elementos extraídos de una investigación pueden hacer innecesaria la fase de instrucción, y no siendo imprescindible la instrucción es posible que se siga la causa por el proceso brevior.

¿Hay una relación entre las investigaciones prejudiciales pastorales y el proceso más breve ante el obispo? Siendo dos novedades de la reforma del proceso promovida por el papa Francisco, ambas habrán de responder al mismo espíritu. El obispo es llamado, de un lado, a ejercer personalmente la justicia y, al mismo tiempo, a compartir con los párrocos el servicio a los fieles que se encuentran en situaciones matrimoniales irregulares y que «por ello hayan abandonado la práctica religiosa ${ }^{67}$. No puede extrañar que en ocasiones se mezclen aspectos en la regulación de estos dos nuevos elementos del proceso matrimonial canónico.

\section{1. ¿Es obligatoria la investigación prejudicial?}

Como hemos visto al principio, en la mayor parte de las diócesis se han dado casos de procesos breviores, pero no hay datos de si éstos han venido precedidos de una investigación prejudicial. Es la indeterminación de lo que exactamente sea la investigación previa la que impide saber con certeza si ésta se ha producido o no, en los casos en los que se ha seguido un proceso más bre-

${ }^{65}$ Para con los fieles en estas situaciones matrimoniales irregulares: «los presbíteros tienen la tarea de acompañar a las personas interesadas en el camino del discernimiento de acuerdo con la enseñanza de la Iglesia y las orientaciones del Obispo», Amoris Laetitia n. 300. Vid. J. Bogarín DíAZ, Repercusiones canónicas de Amoris Laetitia, Revista General de Derecho Canónico y Eclesiástico del Estado 41 (2016) 56-61.

${ }^{66} \mathrm{Vid}$., c. $1683,2^{\circ}$ : «concurran circunstancias de las personas y de los hechos, sostenidas por testimonios o documentos, que no requieran una investigación o una instrucción más precisa, y hagan manifiesta la nulidad».

${ }^{67}$ Reflexiones interesantes sobre esta responsabilidad en E. ZANETTI, La consulenza previa ..., cit., 9. 
ve. Aunque pueda parecer que ya haya transcurrido mucho tiempo desde la entrada en vigor del MIDI, y aunque modificaciones como la eliminación de la confirmación de sentencias declarativas de nulidad surtieron un efecto casi inmediato, hay que pensar que cambiar la actitud para recibir en la comunidad a personas con una situación familiar irregular, no se produce de un día a otro. La doctrina contenida en el cap. VIII de la Exhortación postsinodal Amoris Laetitia ${ }^{68}$, todavía no se ha acomodado entre nosotros y entiendo que hay una relación directa entre el mecanismo de la investigación prejudicialpastoral y esa acogida en la Iglesia a quienes se apartaron de la práctica religiosa por estar en una situación matrimonial irregular de la que se trata en el documento final del Sínodo. Mientras tanto es cierto que algunas de las causas que se han sustanciado por el proceso brevior han sido causas en las que no cabía más instrucción que la que se había realizado y que a la vista de los cambios en materia de apreciación de las pruebas ${ }^{69}$, se han presentado ahora, recurriendo a este proceso más breve.

Sabemos que la investigación prejudicial puede concluir demandando la nulidad del matrimonio por el proceso ordinario o por el proceso más breve, pero ¿es imprescindible que se haya llevado una investigación prejudicial para solicitar el proceso brevior? En principio, si tenemos en cuenta que este tipo de proceso se contempla para causas en las que no se prevé la realización de más instrucción, la lógica indica que alguna indagación previa se habrá debido hacer, dado que no se planea hacer ninguna más y no hay otro tipo de investigación reglada excepto ésta que aparece en los arts. 2 a 5 de las Reglas de Procedimiento. Pero por otra parte los cánones 1683 y 1684 no la exigen como requisito para solicitar que se siga este proceso $^{70}$. Nada obsta en principio a que se pueda acudir a este proceso, si ha sido el abogado por

${ }^{68}$ AAS CVIII, 1 Aprilis 2016, 428-440. Vid. J. Bogarín DíAz, Repercusiones canónicas..., cit., y L. RuANo, Amoris Laetitia: Referencias jurídico-canónicas y su proyección pastoral, Familia Ius Canonicum 54 (2017) 41-67.

69 «En cuanto a las pruebas, no hay novedad sustancial, sino más bien una codificación de lo que venía siendo interpretación y praxis mayoritarias, que quedan así confirmadas con rango legal: La deposición de un solo testigo puede hacer prueba plena si se trata de un testigo cualificado que depone sobre asuntos de su oficio o si las circunstancias de los hechos o de las personas lo indican. Las confesiones judiciales y otras declaraciones de las partes pueden tener valor de prueba plena, teniendo en cuenta los indicios y adminículos existentes y recurriendo si es necesario a testigos sobre la credibilidad de dichas partes». A. M. López MEDinA, Actualidad del ordenamiento jurídico..., cit., 291.

${ }^{70}$ Nos consta que por ejemplo en el tribunal de Denver, EE.UU., siempre se exige una investigación prejudicial para que se admita al proceso brevior. 
ejemplo quien, directamente o sirviéndose de alguna persona, ha realizado indagaciones y ha encontrado gracias a ellas elementos claros para solicitar la nulidad, pero en este caso no estamos ante la investigación que se contempla en el MIDI.

\subsection{Obligatoriedad del litisconsorcio activo}

Para que sea admitida la causa al proceso brevior «la petición debe haber sido propuesta por ambos cónyuges o por uno de ellos, con el consentimiento del otro» ${ }^{71}$. Este requisito puede conectarse con uno de los objetivos que se marca a quien realiza la investigación previa que «debe indagar si las partes están de acuerdo en pedir la nulidad».

Varias de las dudas surgidas en torno a la cuestión del litisconsorcio obligatorio fueron abordadas en las primeras respuestas privadas dadas por el Pontificio Consejo para los Textos Legislativos sobre la reforma del proceso declarativo de nulidad, y que se hicieron públicas en la web de este dicasterio. En octubre de $2015^{72}$, en dos de estas respuestas se aclaraba la necesidad de que la adhesión de ambas partes a la causa fuese expresa. Descartando que pudiese usarse un consentimiento tácito en los casos en los que no se conozca el paradero de la otra.

Arroba Conde hablaba ya en marzo de 2016 del porqué se exige el acuerdo sobre el objeto que sustenta la litis que requiere el MIDI ${ }^{73}$. Si se trata de un proceso extraordinario y abreviado donde no caben más pruebas que las ya recogidas al inicio de la causa, cualquier discordancia entre las partes, de entrada, o sobrevenida, sobre las circunstancias probadas (que no serían pues «probadas» si se ponen en duda) o sobre los capítulos de nulidad invocados (que no pueden variar durante este tipo de proceso), darían al traste con la finalidad del proceso brevior que no admite contraste de posturas. Por último, el hecho de que vaya a ser el obispo quien juzgue es otro dato que aconseja

71 Vid., c. $1683,1^{\circ} \mathrm{CIC}$.

72 Me refiero a las respuestas que se publican con los títulos «On the conversion of the formal process to the processus brevior» Prot. N. 15138/2015, «On the consent of both parties as requirement for the processus brevior (new c. 1683 Mitis Iudex)» Prot. N. 15139/2015. http://www. delegumtextibus.va/content/testilegislativi/it/risposte-particolari/procedure-per-la-dichiarazione-della-nullita-matrimoniale.html (consultado por última vez el 28-III-2017).

${ }^{73}$ M. ARroba Conde, El proceso más breve ante el obispo, en L. RUANO - C. GUZMán (coords.), Reforma de los procesos de nulidad y otras novedades legislativas de derecho canónico y eclesiástico del Estado, Dykinson, Madrid 2017, 249-278. 
este litisconsorcio activo. De otro modo el pastor, aunque fuera en aras de la justicia, se vería obligado a colocarse del lado de una de las partes y por tanto frente a la otra. Una última razón podría argüirse, y que haría necesario el consentimiento expreso de ambos cónyuges para evitar que se denuncie una denegación del derecho de defensa ante la autoridad civil, como ya ha sucedido en alguna ocasión ${ }^{74}$.

Sin embargo, el hecho de que sea necesaria la firma de ambos cónyuges en la demanda ha llevado a algunos, especialmente en Italia, a hablar de consenso entre las partes para obtener la nulidad y de algún modo asimilaron este proceso al de divorcio civil consensuado ${ }^{75}$. Pero ¿qué significa declaración de nulidad consensuada? ¿Es ése el riesgo al que se ve sometido el principio de indisolubilidad del matrimonio en estos casos, el consenso? ${ }^{76}$

Entre los problemas que en la práctica del nuevo proceso se presentan, Bueno Salinas ${ }^{77}$ señalaba la probabilidad de que este litisconsorcio fuese "ficticio" logrado no tanto por la conformidad auténtica de ambas partes, sino obtenida mediante algún pacto que, sin ser ilícito, contente a la parte remisa quizá a plantear la nulidad (piénsese por ejemplo en otorgar unas ventajas en la disolución de la sociedad de gananciales, cesión de la vivienda familiar, régimen de visitas a los hijos, etc.). La necesidad de obtener la conformidad del

${ }^{74}$ En este punto vid. E. TAWIL, Le motu proprio Mitix Iudex au regard de l'arret Pellegrini de la CEDH, en C. Dounot - F. Dussaubat (coords.), La réforme des nullités de mariage: une étude critique, Lethielleux Editions, Paris 2016, 210 y ss. Otros problemas podrían plantearse cuando se trata de dar efectos civiles a estas sentencias de nulidad, vid. L. SABBARESE - R. SANTORO (eds.), Il processo matrimoniale più breve. Disciplina canonica e riflessi concordatari, Dehoniane, Bolonia 2016, 85 y ss.

75 En este sentido vid. E. DI Bernardo, Problemi e criticità della nuova procedura, en AA. VV., La riforma del processo matrimoniale..., cit., 127. Lógicamente en estos casos se está olvidando que siempre habrá una parte contraria que será el Defensor del vínculo.

${ }^{76}$ Esto parece afirmar Ferrer al decir: «No se nos oculta que estamos ante una medida innovadora y que ha suscitado reservas», para inmediatamente recordar las palabras del papa Francisco. J. FERRER, Valoración de las circunstancias que pueden dar lugar al proceso abreviado, Ius Canonicum 56 (2016) 162.

77 «El proceso breve, como novedad procesal, deberá irse aplicando y desarrollando según enseñe la práctica, pero la formulación actual plantea ya ciertas cuestiones problemáticas: a) cómo asegurarse de que el litisconsorcio (o el consentimiento) sea auténtico y no forzado o meramente formal, y evitar asimismo el fraude de ley; b) cómo conjugar la presencia de prueba inicial segura con los ejemplos que ofrece el art. 14, $\$ 1$ de las Reglas de procedimiento que incluye el motu proprio; c) si la presencia del obispo diocesano como juzgador ha de contribuir realmente a la celeridad del proceso». S. BuENO SALINAS, La reforma de los procesos canónicos de declaración de nulidad de matrimonio. La celeridad del proceso, Revista General de Derecho Canónico y Eclesiástico del Estado 40 (2016) 8. 
otro cónyuge podría llevar al redactor de la demanda a silenciar determinados hechos, pues de ponerlos de manifiesto entiende probable que la otra parte no consentiría firmarla.

Por eso se trae aquí la enigmática frase que aparece en el proemio del MIDI, precisamente en el punto IV al referirse al proceso brevior: «No se me escapa, sin embargo, cuánto un juicio abreviado pueda poner en riesgo el principio de la indisolubilidad del matrimonio» ${ }^{78}$. Si se ha seguido una investigación antes de comenzarlo, y la ha llevado a cabo una persona en la que ha confiado el obispo, los resultados de esta investigación aun no siendo concluyentes (hay que recordar que sólo el proceso judicial se ha de pronunciar acerca de la validez o no del matrimonio) en cualquier caso serán fiables, esto es, gracias a esta investigación pastoral se pueden descartar dudas que en buena y humana lógica se presentan acerca de la sinceridad del consentimiento de ambas partes para acceder a este proceso o de la honradez con la que se hubieran podido hacer las indagaciones o presentar los resultados. Quizá fuese conveniente que la persona que haya hecho estas investigaciones comparezca en la sesión en la que se dilucidará la causa. Nada parece que obste a ello, toda vez que el c. 1685 establece que el instructor debe citar a «todos aquellos que deben participar». ¿Qué efecto debe tener el testimonio de la persona que se encargó de la investigación ${ }^{79}$ ? Pues habrá que dejarlo a la prudencia del propio instructor. Si ha preparado un memorial sobre los resultados de sus indagaciones, y ese documento se ha aportado como prueba, será lógica su presencia como autor de éste ${ }^{80}$.

78 «Nos tamen non latuit, in quantum discrimen ex breviato iudicio principium indissolubilitatis matrimonialis adduci possit», Francisco, Motu Proprio Mitis Iudex Dominus Iesus, AAS CVII (2015) 960.

79 «El contexto sinodal, por el reforzamiento pastoral de la actividad judicial que conlleva, induce a considerar el aprovechamiento de la investigación previa como un objetivo de gran calado para poder contar con la aportación del testimonio de credibilidad que pueden ofrecer el párroco o los profesionales que intervinieron en ella. Tal testimonio se relaciona sólo con la credibilidad subjetiva de la parte, no con su credibilidad objetiva, teniendo presente además que la investigación se realiza en un tiempo cercano al proceso y, por tanto, en el límite del comienzo del tiempo sospechoso». M. ARROBA CONDE, La experiencia sinodal y la reciente reforma procesal en el Motu proprio Mitis Iudex Dominus Iesus, Anuario de Derecho Canónico Suplemento 5 (2016) 186.

80 «El vicario judicial citará para la sesión instructora a "todos cuantos deban participar en ella" (can. 1685 CIC), entre los que se encuentran, además de las partes y los testigos (incluso los autores de documentos privados que deban ser reconocidos o de informes periciales o médicos que haya que ratificar)». C. GUZMáN, Instrucción y decisión de la causa en el proceso abreviado ante el obispo. Práctica de los tribunales eclesiásticos españoles, Estudios eclesiásticos 92 (2017) 611-612. 


\subsection{La gratuidad de los procesos}

$¿$ Cabe relacionar estas dos cuestiones, investigación prejudicial y proceso brevior, con la gratuidad de las causas canónicas? A la vista de la indefinición de los fines de la investigación prejudicial no ha faltado quien lo relacio$\mathrm{ne}^{81}$. También porque es lógico plantearse, después de haber hablado de la especialización y de la dedicación que supone encargarse de la investigación prejudicial, que el llevarla a cabo supone un esfuerzo económico, piénsese en esa adaptación de los COF para que desde allí se formase a personas capaces de realizarlas. Los tribunales tienen fijados el importe de sus tasas y los casos de exención (también las situaciones en las que se les proporciona asistencia letrada gratuita) y con ello prevén cubrir los gastos de funcionamiento. ¿Debe suceder lo mismo con estos servicios de investigación pastoral? De una lectura atenta de algunos documentos que podríamos llamar precursores de la reforma, se puede desprender que se preveía algo en este sentido.

En el Instrumentum Laboris elaborado en 2014, al abordar el tema de la simplificación de las causas matrimoniales mencionaba la «reducción del costo económico». En efecto en los nn. 48 y 49 de la Relatio del Sínodo Extraordinario sobre la Familia, ya se hacía referencia a la gratuidad, distinguiendo entre la gratuidad del proceso y de las consultas previas ${ }^{82}$.

Por otra parte, en el Instrumentum Laboris del Sínodo de 2015 se puede leer en relación a lo primero: «Se observa un amplio consenso sobre la oportunidad de hacer más accesibles y ágiles, posiblemente gratuitos, los procedimientos para el reconocimiento de los casos de nulidad matrimonial» ${ }^{83}$; mientras que en relación con lo segundo, la propuesta es que «en cada diócesis se garanticen, de manera gratuita, los servicios de información, asesoramiento y mediación relacionados con la pastoral familiar, especialmente a disposición

81 «Lo cierto es que en parte alguna se concreta positivamente cuáles vayan a ser las estructuras eclesiales de las que se habla, cómo haya de ser su proceder, ni tampoco por qué vía y en qué medida los resultados de lo que se denomina una "investigación prejudicial pastoral previa al proceso" (cfr. los artículos 2 a 5 de las Reglas de procedimiento), vaya luego en su caso a integrarse en el proceso judicial canónico propiamente dicho. En ese marco, por cierto, parece insertarse la invitación que se hace en el texto pontificio que apunta a orientarse hacia una "gratuidad" de los procesos». R. Rodríguez ChaCón, Principales novedades en el proceso canónico de nulidad matrimonial tras la reforma del Papa Francisco, Revista de Derecho de Familia, 1 de septiembre de 2016.

82 M. ARroba CONDE, Le proposte di snellimento dei processi matrimoniali nel recente Sinodo, en L. SABBARESE (a cura di), Sistema matrimoniale canonico in synodo, Urbaniana University Press, Ciudad del Vaticano 2015, 76.

83 Instrumentum Laboris, n. 115. 
de personas separadas o de parejas en crisis. Un servicio así cualificado ayudaría a las personas a emprender el recorrido judicial, que en la historia de la Iglesia resulta ser el camino de discernimiento más acreditado para verificar la validez real del matrimonio» ${ }^{84}$.

La posibilidad de que los procedimientos judiciales eclesiásticos sean gratuitos ya existe. Al menos ya existe en España, pues es cierto que en otros lugares esto puede no ser así, pero en nuestro país está prevista la fórmula para que quien no cuente con medios económicos para proponer o personarse en una causa de nulidad pueda hacerlo, aunque quizá suceda que muchos fieles cristianos españoles lo desconozcan. La intención de la Iglesia es que esto siga siendo así y que este sistema se extienda a otros países, especialmente los que tienen una cultura jurídica diferente. Pero por otra parte está el servicio de acompañamiento familiar y de asesoramiento en estas materias (que eventualmente podrá incluir a las personas idóneas para la realización de las investigaciones prejudiciales, o al menos la tarea de suministrar la formación adecuada para quienes la realizan) y que se plantea como gratuito para todos los fieles. Ofrecer un servicio de orientación pastoral-familiar es caro, seguramente mantenerlo resulta más gravoso que mantener un tribunal eclesiástico, pues habrá de contar con especialistas en diversas materias y tener sus puertas abiertas de manera constante.

En el Subsidio Aplicativo no parece que se siga la diferenciación que sí se aprecia en los documentos sinodales que propone la posibilidad de una justicia gratuita para quienes lo necesiten, y además también un servicio general gratuito de asesoría a los matrimonios dentro del cual se atienda a quienes están separados civilmente o divorciados. El texto del Subsidio deja además abierto un interrogante al invocar la generosidad de los fieles con las causas de los pobres ${ }^{85}$. Es difícil pensar en establecer una aportación voluntaria para sostener el coste de las causas de quienes carecen de medios, es mucho más sencillo seguir equilibrando los ingresos y los gastos del tribunal para poder atender y re-

84 Instrumentum Laboris, n. 117.

85 Ayudarán también, salvada la justa y digna retribución de los operadores de los tribunales, a que sea asegurada dentro de lo posible la gratuidad de los procedimientos. Deberán, por lo tanto, donde sea necesario, actualizar la distribución de los medios económicos disponibles cooperando en la búsqueda de los recursos necesarios para los tribunales diocesanos. Se dejará a la justa sensibilidad de los pastores y de quienes atienden los tribunales la posibilidad de solicitar a las partes, con tacto pastoral, una contribución para la causa de los pobres. Ellos serán ciertamente generosos para que el perfume de la caridad impregne la mente y el corazón de los fieles de la Iglesia. Subsidio Aplicativo, 12. 
bajar o suprimir las tasas a aquellos que lo necesitan. Quizá este párrafo del Subsidio se pueda referir a solicitar una contribución económica en vez de una tasa fijada en los juicios más breves, que con unos trámites tan simplificados deben resultar mucho menos gravosos. Además, siendo el obispo el juez, quizá desde algún punto de vista pudiera apreciarse inadecuado que por su actuación se requiriera unas tasas determinadas. Por lo que puedo comprobar tras consultar las tasas publicadas de varios tribunales españoles, no hay una tasa fijada para el proceso brevior $^{86}$. También podría resultar lógico que se tratara de pedir donativos destinados a los servicios de asesoramiento general o que se solicitara una contribución económica voluntaria por haberse realizado la investigación prejudicial. De cualquier modo, se trata únicamente de ideas que me sugiere la lectura de las normas. Sin embargo, hay que apuntar que se constata una preocupación por el tema de las tasas en las contestaciones a la encuesta realizada desde la Asociación Española de Canonistas. Son once los tribunales españoles de los que responden a la encuesta que han suprimido las tasas frente a otros treinta que las mantienen, una situación que, según reconocen los miembros de los tribunales, crea confusión entre los propios fieles ${ }^{87}$.

\section{CONCLUSIÓN}

A modo de conclusión cabe decir que, dos años después de la entrada en vigor del MIDI, nada o muy poco se ha hecho para promocionar la investigación prejudicial prevista aquí para salir al encuentro de quienes se alejaron de

${ }^{86}$ En el tribunal de Denver en EE.UU., del que ya hemos hablado, las tasas del proceso brevior están fijadas en 100 dólares (frente a las 550 que importan en el proceso ordinario). En este tribunal se establece una contribución testimonial de 25 dólares por asesoramiento acerca de los procesos. También es interesante la advertencia que realizan: «No es nuestro deseo crear dificultades financieras a nadie o dar la impresión de que se puede comprar una declaración de nulidad. Por el contrario, seremos sensibles a su situación financiera y nunca se le negará a nadie una declaración de nulidad por la imposibilidad de pagar. Si necesita fraccionar el pago, comuníquese con nuestra oficina. La mayoría de los fieles no saben que el gasto que supone para la Archidiócesis de Denver cada causa de nulidad es de $\$ 1,500$. Gracias a la generosidad de los feligreses de la Archidiócesis, ésta puede asumir la mayor parte de este gasto. Aun así, es justo que quienes soliciten nuestros servicios hagan una contribución apropiada y compartan este costo». De la página web del tribunal de la Archidiócesis de Denver http://archden.org/wp-content/uploads/2015/12/payment-schedule-12-16-15.pdf (consultado por última vez el 28 de marzo de 2018).

87 «n bastantes casos, los respectivos Vicarios judiciales han señalado en la sección dedicada a las "observaciones" que consideran necesario que en esta materia haya directrices concretas de la Conferencia Episcopal Española (...) a fin de que no existan desigualdades entre los Tribunales de las diversas diócesis en el territorio nacional, unos que han suprimido las tasas y otros que las mantienen». R. RODRíGUEZ CHACÓN, Resultados de la encuesta..., cit., 302. 
la Iglesia a causa de un fracaso matrimonial ante el que recurrieron al divorcio y que sinceramente quieren acercarse de nuevo a ella, quizá junto a una familia que han formado después. La pastoral matrimonial, y no tanto los tribunales eclesiásticos, debe abrir caminos para que estas personas puedan participar de la vida de la Iglesia y no hay que olvidar que entre los instrumentos que los pastores ponen al servicio de este fin, también se encuentra el Derecho. Una aplicación recta, justa y profesional de las normas puede ofrecer un camino de retorno de estas personas y sus familias al seno de la Iglesia. Dadas las particularidades de cada sociedad, corresponde a los obispos de cada país señalar el mejor modo de llevar a cabo las investigaciones pastorales-prejudiciales, que bien orientadas y en el marco de otras aspiraciones de la reforma de las causas matrimoniales (celeridad, gratuidad, etc.) deben contribuir a reforzar el matrimonio sacramento. 


\section{Bibliografía}

AA. Vv., La riforma del processo matrimoniale ad un anno del Motu Proprio Mitis Iudex Dominus Iesus, Libreria Editrice Vaticana, Ciudad del Vaticano 2017.

Alwan, H., Les enjeux de l'application du motu proprio Mitis et misericors Iesus par les tribunaux ecclésiastiques en orient specialementau Liban, Reveu du Droit Canonique 67 (2017) 191-218.

ARRoBa CONDE, M., Le proposte di snellimento dei processi matrimoniali nel recente Sinodo, en L. SABbARESE (a cura di), Sistema matrimoniale canonico in synodo, Urbaniana University Press, Ciudad del Vaticano 2015, 61-85.

—, La experiencia sinodal y la reciente reforma procesal en el Motu proprio Mitis Iudex Dominus Iesus, Anuario de Derecho Canónico Suplemento 5 (2016) 165-191.

—, La pastoral judicial y la preparación de la causa en el Motu Proprio Mitis Iudex Dominus Iesus, en M. E. Olmos (ed.), Procesos de nulidad matrimonial tras la reforma del Papa Francisco, Dykinson, Madrid 2016, 63-82.

—, El proceso más breve ante el obispo, en L. RUANO - C. GuZMán (coords.), Reforma de los procesos de nulidad y otras novedades legislativas de derecho canónico y eclesiástico del Estado, Dykinson, Madrid 2017, 249-278.

Bernárdez Cantón, A., Parte General de Derecho Canónico, Centro de Estudios Ramón Areces, Madrid 1998.

Bogarín Díaz, J., Repercusiones canónicas de Amoris Laetitia, Revista General de Derecho Canónico y Eclesiástico del Estado 41 (2016) 1-64.

Bueno Salinas, S., La reforma de los procesos canónicos de declaración de nulidad de matrimonio. La celeridad del proceso, Revista General de Derecho Canónico y Eclesiástico del Estado 40 (2016) 1-17.

Capucci, G. - Fanella, A., L'attuazione del Motu Proprio Mitis Iudex Dominus Iesus nell'esperienza del tribunale metropolitano dell'arcidioceci di Denver-Colorado-USA, en AA. Vv., La riforma del processo matrimoniale ad un anno del Motu Proprio Mitis Iudex Dominus Iesus, Libreria Editrice Vaticana, Ciudad del Vaticano 2017, 173-184.

DE LEÓN REY, E., La tramitación de los procesos de nulidad: consulta previa e inmediación, en S. Sánchez Maldonado (ed.), IX Simposio de Derecho Matrimonial y Procesal Canónico. Granada 24 a 26 de septiembre de 2015, Arzobispado de Granada, Granada 2016, 139-150.

Del Pozzo, M., Il processo matrimoniale più breve davanti al vescovo, PUSC, Roma 2016. 
Di Bernardo, E., Problemi e criticità della nuova procedura, en AA. Vv., La riforma del proceso matrimoniale ad un anno del Motu Proprio Mitis Iudex Dominus Iesus, Libreria Editrice Vaticana, Ciudad del Vaticano 2017, 109152.

FABRIS, C. M., Indagine pregiudiziale o indagine pastorale nel motu proprio Mitis Iudex Dominus Iesus. Novitá normative e profili problematici, Ius Ecclesiae 28 (2016) 479-503.

FERRER, J., Valoración de las circunstancias que pueden dar lugar al proceso abreviado, Ius Canonicum 56 (2016) 157-192.

Gallego Pérez, J., Los tribunales eclesiásticos españoles, en AA. Vv., Curso de Derecho matrimonial y procesal canónico para profesionales del foro. XV Simposio de Derecho matrimonial canónico, UPSA, Salamanca 2000, 431-489.

Glaubitz, E., L'attuazione del Motu Proprio Mitis Iudex Dominus Iesus nell'esperienza dei tribunali ecclesiastici tedeschi, en AA. VV., La riforma del proceso matrimoniale ad un anno del Motu Proprio Mitis Iudex Dominus Iesus, Libreria Editrice Vaticana, Ciudad del Vaticano 2017, 185-193.

Gullo, C., Comentario al can. 1490, en Comentario Exegético al Código de Derecho Canónico, Eunsa, Pamplona 1997, vol. IV/1, 1065.

GuZMán, C., Instrucción y decisión de la causa en el proceso abreviado ante el obispo. Práctica de los tribunales eclesiásticos españoles, Estudios eclesiásticos 92 (2017) 603-641.

LlOBELL, J., Cuestiones acerca de la apelación y la cosa juzgada en el nuevo proceso de nulidad del matrimonio, Anuario de Derecho Canónico Suplemento 5 (2016) 53-96.

López Medina, A. M., Actualidad del ordenamiento jurídico de la Iglesia en el año 2015, en L. RUANO - C. GUZMán (coords.), Reforma de los procesos de nulidad y otras novedades legislativas de derecho canónico y eclesiástico del Estado, Dykinson, Madrid 2017, 289-337.

Moreno, P. A., El servicio de indagación prejudicial, Ius Canonicum 56 (2016) 65-85.

NúÑEZ, G., La fase preliminar del nuevo proceso de nulidad, Ius Canonicum 57 (2017) 9-44.

PinTo, P. V., Matrimonio y Familia en el camino sinodal del Papa Francisco, Edigráficas Mariana E.U., Bogotá 2017.

REgORDÁN, F. J., La investigación preliminar en las nuevas normas procesales del Motu Proprio Mitis iudex dominus Iesus, Anuario de Derecho Canónico Suplemento 5 (2016) 65-85. 
Rodríguez Chacón, R., Principales novedades en el proceso canónico de nulidad matrimonial tras la reforma del Papa Francisco, Revista de Derecho de Familia, 1 de septiembre de 2016.

—, Resultados de la encuesta realizada por la Asociación Española de Canonistas sobre la aplicación de MIDI en su primer año de vigencia en los tribunales eclesiásticos españoles, en L. RuANO - J. L. SÁnCHEZ GIRÓN (eds.), Novedades de Derecho canónico y Derecho eclesiástico del Estado. A un año de la reforma del proceso matrimonial, Dykinson, Madrid 2017, 295-320.

Ros Corcoles, J., El Vicario judicial y el instructor en los procesos de nulidad matrimonial tras el Motu Proprio Mitis Iudex, Ius Canonicum 56 (2016) 87-103.

RuAno, L., Amoris Laetitia: Referencias jurídico-canónicas y su proyección pastoral, Familia 54 (2017) 41-67.

SABbarese, L. - SANTORO, R., Il processo matrimoniale più breve. Disciplina canonica e riflessi concordatari, Dehoniane, Bolonia 2016.

TAWIL, E., Le motu proprio Mitix Iudex au regard de l'arret Pellegrini de la CEDH, en C. Dounot - F. Dussaubat (coords.), La réforme des nullités de mariage: une étude critique, Lethielleux Editions, Paris 2016, 210 y ss.

Tribunal Apostólico De la Rota Romana, Subsidio aplicativo del Motu Proprio Mitis Iudex Dominus Iesus, Ciudad del Vaticano 2016.

ZANETTI, E., La consulenza previa all'introduzione di una causa, en REDAZIONE DI QUADERNI DI DIRITTO ECCLESIALE (a cura di), La riforma dei processi matrimoniali di Papa Francesco. Una guida per tutti, Ancora, Milano 2016, 9-27. 
